\title{
Neue Herausforderungen für das Controlling
}

\author{
Kongressmesse ReWeCo des BVBC vom 28. bis 30. Mai in der Congress Union Celle - \\ Aktuelle Trends aus der Praxis, innovative Lösungen und Karrierechancen
}

Der Informationsbedarf im Finanz- und Rechnungswesen wird immer größer: $\mathrm{Ne}$ ben schnell wechselnden Bestimmungen gewinnen internationale Anforderungen wie IFRS oder US-GAAP an Bedeutung. Zudem überprüfen viele Unternehmen im Zuge der Finanzkrise ihr eigenes Risikomanagement. Antworten auf drängende Fragen liefert die Kongressmesse ReWeCo, die vom 28. bis 30. Mai in der Congress Union Celle stattfindet.

Fach- und Führungskräfte aus ganz Deutschland treffen sich Ende Mai in der Residenzstadt Celle zur dreitägigen Kongressmesse $\mathrm{ReWeCo}$, die eine breite Orientierung in allen Belangen des Finanz- und Rechnungswesens bietet. Unter der Regie des Bundesverbandes für Bilanzbuchhalter und Controller (BVBC) referieren Experten aus Wissenschaft, Politik und Praxis über aktuelle Herausforderungen. Parallel dazu präsentieren über 50 Aussteller innovative Produktund Servicelösungen.
Unter dem Motto „Über Grenzen hinweg am Ball bleiben“" widmet sich die ReWeCo wichtigen unternehmerischen Fragen. Gerade kleine und mittelgroße Unternehmen haben einen umfassenden Informationsbedarf im Finanz- und Rechnungswesen. Oft fehlt eine eigene Stabsabteilung, die sich über die zunehmend komplexen Anforderungen auf dem Laufenden hält. Auf der ReWeCo können Fach- und Führungskräfte eigene Wissenslücken schließen und effiziente Lösungen kennenlernen.

Das Risikomanagement ist ein zentrales Thema auf der ReWeCo. Besucher lernen in Fachvorträgen, mögliche Risiken zu identifizieren, eigene Schwachstellen frühzeitig zu erkennen und wirksame Gegenmaßnahmen zu treffen. Noch sind die Chancen des Risikomanagements als strategisches Instrument der Unternehmensführung weitgehend unerkannt. Letztlich können Führungskräfte mithilfe von geeigneten Reporting- und Analysesyste- men wichtige Management-Entscheidungen vorbereiten und absichern.

Für Berufseinsteiger und karrierebewusste Fachkräfte ist die ReWeCo eine wichtige Anlaufstelle. Hier können sie sich einen Überblick über geeignete Qualifizierungsmaßnahmen von öffentlichen und privaten Bildungseinrichtungen verschaffen. Zudem können sie sich mit Branchen-Insidern offen austauschen und Optionen für ihre berufliche Weiterentwicklung erörtern.

Die Redaktion der ZfCM hat mit dem Bundesverband der Bilanzbuchhalter und Controller eine besondere Vereinbarung getroffen: Die Leser der ZfCM können beim BVBC ihre persönliche kostenfreie Messekarte (im Gegenwert von 20 Euro) per Fax: 02 28 / 963 93 -14 oder per E-Mail: redling@bvbc.de anfordern. Weitere Infos sind unter http://www.reweco.de $\mathrm{zu}$ finden.

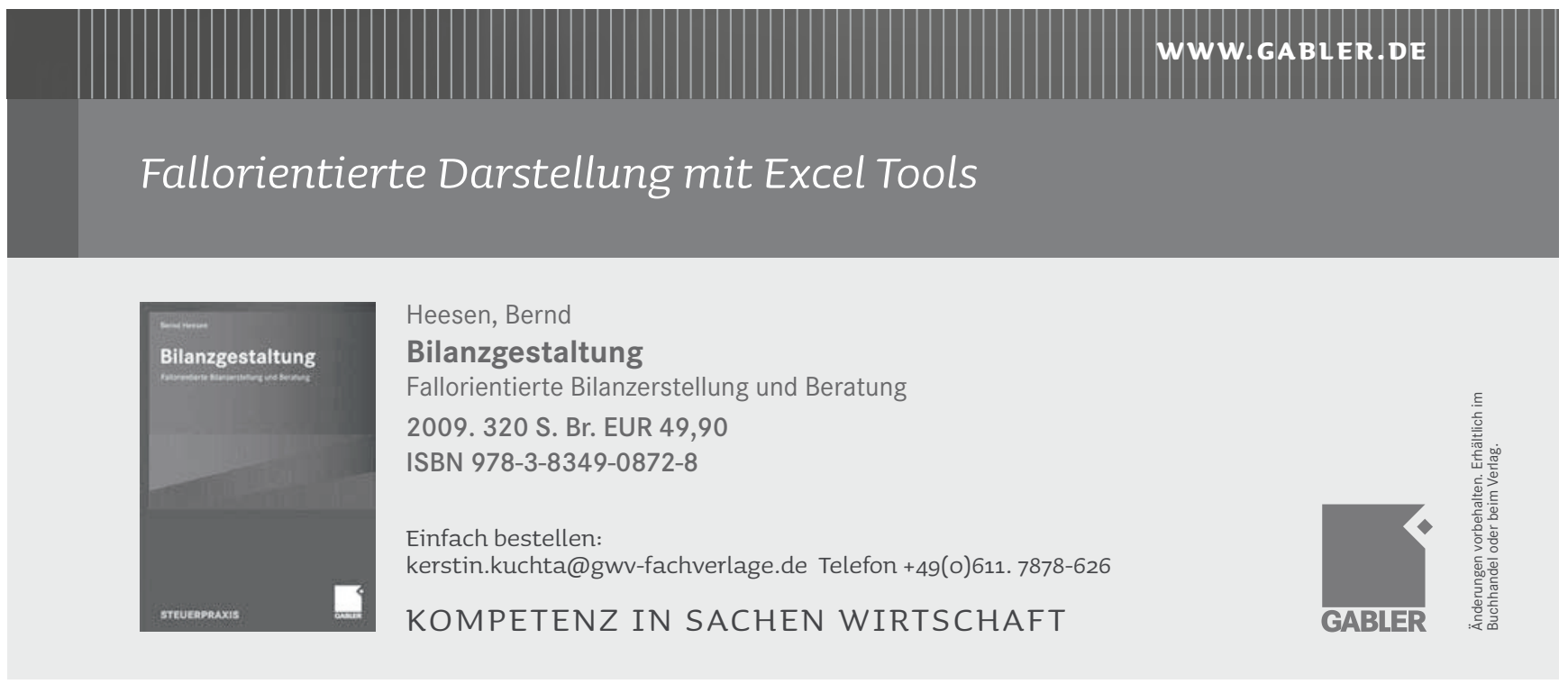

